Journal of Clinical Investigation

Vol. 41, No. 6, 1962

\title{
THE ACCELERATION OF THROMBUS FORMATION BY CERTAIN FATTY ACIDS *
}

\author{
By WILLIAM E. CONNOR
}

(From the Cardiovascular Research Laboratories, the Department of Internal Medicine, State

University of Iowa College of Medicine, Iowa City, Iowa)

\section{(Submitted for publication November 2, 1961 ; accepted December 17, 1961)}

Lipids have long been known to exert important effects upon blood coagulation. The crude cephalin of Howell accelerated clotting (2), whereas the extraction of lipid from plasma by Macfarlane, Trevan and Attwood inhibited its coagulation (3). Many studies have stressed the role of phospholipids in coagulation. Indeed, thromboplastin generation will not occur without optimal concentrations of phospholipid (4).

In 1955 Poole showed that the addition of fatty acids to citrated plasma shortened the clotting time (5). Others have confirmed these findings $(6,7)$. The concentrations of fatty acids used were within the range of the unesterified fatty acids circulating in man. The pathological significance of these effects on clotting have remained uncertain. Nevertheless, some experimental and clinical observations suggest that fatty acids may in some way influence thrombosis (8-10).

Recently Chandler (11) has devised a technique for making artificial thrombi in a rotating, circular plastic tube. These thrombi have a white head of platelets and leukocytes and a long fibrin tail containing trapped red blood cells. They are similar in microscopic appearance to the thrombi occurring in human thromboembolic disease (11). Hitherto, blood clotting tests have usually been performed with stagnant blood in glass tubes. The resulting blood clots consist only of a fibrin network without conspicuous cellular elements and have little microscopic resemblance to the thrombi occurring in disease.

When this in vitro thrombus-producing system is suitably modified, the time required for formation of a thrombus is highly reproducible $(12,13)$. The use of this system then provides another tool

* Presented in part at the Annual Meeting of the Federation of American Societies for Experimental Biology, Atlantic City, N. J., April 12, 1961 (1). Supported by research grants from the National Institutes of Health (H-4621), and the Iowa and American Heart Associations. for the study of blood clotting, with the end point of the test being termed the "thrombus-formation time."

Connor and Poole have found that the thrombus-formation time of rat blood was shortened greatly by the addition of long chain, saturated fatty acids but was unaffected by either short chain, saturated fatty acids or by long chain, unsaturated fatty acids (13). In the present investigation these earlier observations were extended with the use of human blood and with additional fatty acids. Furthermore, evidence was found that the acceleration of thrombus formation by certain fatty acids probably occurred through the activation of the Hageman factor.

\section{METHODS}

Blood. Venous blood was drawn from normal human subjects 1 hour after breakfast or lunch. Special care was taken in obtaining and processing the blood to avoid complete activation of the Hageman or "glass" factor. It was assumed that some activation did occur but that, with the techniques employed, the amount of activation was consistent from one subject to another. Each venipuncture was made with a new 18 gauge, silicone-coated needle, ${ }^{1}$ and the blood was channeled through a 2 inch length of new plastic tubing. ${ }^{2}$ If the venipuncture was difficult or if blood did not flow freely, a new attempt was made in a different vein. The first $3 \mathrm{ml}$ of blood was discarded to dispose of any tissue juice introduced by the venipuncture. Blood was collected in chilled siliconecoated glass tubes with $4.5 \mathrm{ml}$ of blood to $0.5 \mathrm{ml}$ of 3.8 per cent trisodium citrate solution. The tubes were capped with Parafilm and inverted for mixing. The blood was then kept in melting ice in a $4^{\circ} \mathrm{C}$ refrigerator until testing when it was warmed to room temperature. Blood stored in this way gave consistent results when tested from 10 minutes to 2 hours after venipuncture. Room temperature in this study was always 22.5 to $23.5^{\circ} \mathrm{C}$.

Duck blood was obtained from the wing veins of Peking drakes and processed in exactly the same way.

Apparatus. The testing apparatus consisted of a

1 Cutter Laboratories, Berkeley, Calif.

2 Mayon Plastics, Hopkins, Minn. 


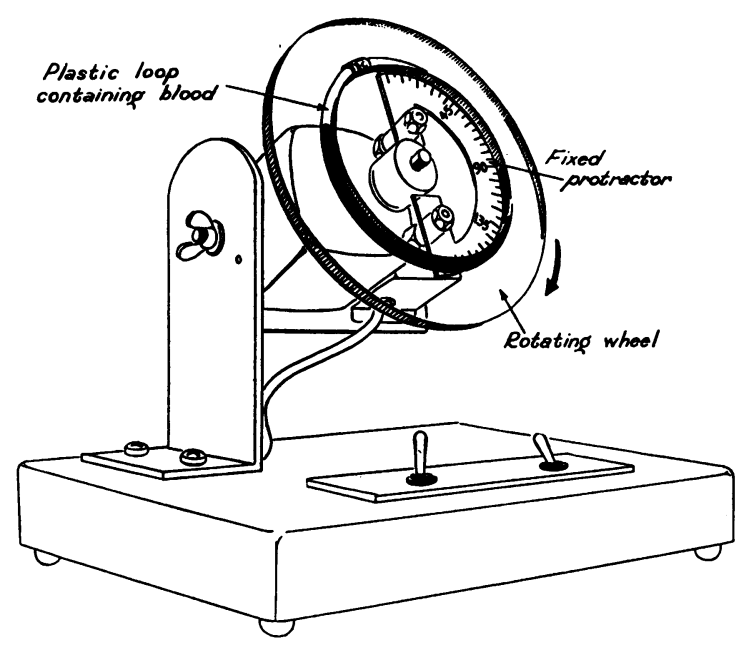

Fig. 1. Apparatus USED FOR PRODUCING thrombi. A length of plastic tubing containing blood has been placed upon the wheel.

plastic disc rotated by an attached motor at $12 \mathrm{rpm}$ (13). The disc was set at $80^{\circ}$ from the horizontal (see Figure 1). For the performance of a test, blood was put into a 12.5 inch length of polyvinyl chloride tubing ${ }^{3}$ having an inside diameter of $0.118 \mathrm{inch}$. The ends of the tube were joined closely by a tightly fitting coupling of polyethylene. ${ }^{4}$ The closed loop was then placed around the disc and rotated. With rotation of the loop, the equivalent motion of the enclosed blood was in the opposite direction.

Reagents. The fatty acids used were the purest available. Oleic, linoleic, linolenic, and arachidonic fatty acids 5 were obtained in vacuum-sealed glass ampules. The saturated fatty acids were supplied by the Hormel Institute ${ }^{5}$ (C16, C18), Distillation Products ${ }^{6}$ (C6-C14), and Nutritional Biochemicals ${ }^{7}$ (C20, C22, hydroxystearate).

The fatty acids were converted to their sodium or potassium salts by gentle warming with sodium or potassium hydroxide (13). The $\mathrm{pH}$ was then adjusted to 8.0 with $0.1 \mathrm{~N} \mathrm{HCl}$. The fatty acid concentration was 0.1 per cent unless otherwise indicated.

The results given were from tests performed with the sodium salts of fatty acids; however, the potassium salts gave identical results. Sodium chloride of molarity and $\mathrm{pH}$ comparable to the $\mathrm{NaCl}$ contained in the fatty acid solution was used as a control testing substance. Physiological saline was also found to be a suitable control.

Bentonite, kaolin, and quartz glass (silica 80-120 mesh)

${ }^{3}$ MacBick Co., Cambridge, Mass.

4 PE 380, Clay-Adams, Chicago, IIl.

5 Oleic, linoleic, and linolenic, from the Hormel Institute, Austin, Minn.; arachidonic from Nutritional Biochemicals Co., Cleveland, Ohio.

6 Distillation Products, Rochester, N. Y.

${ }^{7}$ Nutritional Biochemicals Co., Cleveland, Ohio. were obtained from commercial sources 8 and used in $10-\mathrm{mg}$ amounts unless stated otherwise. Bentonite and kaolin gave identical results in amounts from 2 to $10 \mathrm{mg}$. Soybean phosphatide ${ }^{9}$ was prepared to a concentration of 0.1 per cent in physiological saline.

Experimental procedure. One $\mathrm{ml}$ of citrated blood was pipetted with a silicone-coated pipet into the plastic tubing, followed by $0.1 \mathrm{ml}$ of either the sodium salt of the fatty acid or the $\mathrm{NaCl}$ control. The loop was then closed and rotated for 1 minute to allow mixing to occur. It had been shown previously that a 1-minute incubation period of the fatty acid and blood was necessary for maximal activity to develop (5). The mixture was recalcified then by adding $0.1 \mathrm{ml}$ of $0.25 \mathrm{M} \mathrm{CaCl}_{2}$, and the loop was rotated again for the test. At this point the timing for thrombus formation was started.

As the loop rotated, a certain angle of the advancing edge of the column of blood in the loop could be observed in relation to the fixed protractor. Readings of this angle were taken every 30 seconds. At the time of thrombus formation within the loop the angular position of the column of blood would shift to a lower position (4 or more degrees), as has been described previously (13). This end point, called the thrombus-formation time, was brought about by an increased friction between the inner wall of the tube and the column of blood which had changed its physical state. That the end point did, in fact, represent thrombus formation could be demonstrated readily when the contents of a loop were poured out and examined.

The tests with glass, bentonite, and kaolin were performed by first dispersing a measured amount of the dry substance within the length of the test plastic loop and then adding blood for the 1-minute period of incubation before recalcification.

Further tests of the fatty acids were made in other blood coagulation systems. The conventional Lee-White whole blood clotting time in plain glass and in siliconecoated glass tubes (14) was altered by placing $0.1 \mathrm{ml}$ of a fatty acid salt in the tubes before adding the blood. In this test $0.1 \mathrm{ml}$ of physiological saline served as a control. The effects of fatty acids in the thromboplastin generation test (4) were studied by replacing successively the aged serum, the barium sulfate-adsorbed plasma, and the source of platelet factor 3 with a fatty acid salt.

\section{RESULTS}

Long chain, saturated fatty acids greatly accelerated the thrombus-formation time. Figure 2 depicts the individual results obtained from the testing of stearic acid in 13 subjects. The control $\mathrm{NaCl}$ thrombus-formation times averaged $8.3 \mathrm{~min}$ utes. With stearic acid, thrombus formation was shortened to a mean of 2.9 minutes or almost one-

\footnotetext{
${ }^{8}$ Fisher Scientific Co., Chicago, Ill.

${ }^{9}$ Gliddex O, The Glidden Co., Chicago, Ill.
} 
TABLE I

Effect of fatty acids and other substances upon the thrombus-formation time

\begin{tabular}{|c|c|c|c|c|}
\hline \multirow[b]{2}{*}{ Test substance } & \multirow{2}{*}{$\begin{array}{l}\text { No. of } \\
\text { tests }\end{array}$} & \multicolumn{3}{|c|}{$\begin{array}{c}\text { Thrombus-formation } \\
\text { time }\end{array}$} \\
\hline & & Mean & SD & p Value* \\
\hline & \multicolumn{4}{|c|}{$\min$} \\
\hline Control $(\mathrm{NaCl})$ & 13 & 8.33 & 0.65 & \\
\hline \multicolumn{5}{|l|}{ Saturated fatty acids: } \\
\hline $\begin{array}{l}\text { C22:0 Behenic } \\
\text { C20:0 Arachidic } \\
\text { C18:0 Stearic } \\
\text { Hydroxystearic } \\
\text { C16:0 Palmitic } \\
\text { C14:0 Myristic } \\
\text { C12:0 Lauric } \\
\text { C10:0 Decanoic } \\
\text { C8:0 Octanoic } \\
\text { C6:0 Caproic }\end{array}$ & $\begin{array}{r}5 \\
9 \\
13 \\
5 \\
9 \\
6 \\
9 \\
6 \\
6 \\
7\end{array}$ & $\begin{array}{l}2.40 \\
2.74 \\
2.95 \\
2.76 \\
4.77 \\
5.27 \\
6.81 \\
7.25 \\
7.30 \\
7.81\end{array}$ & $\begin{array}{l}0.37 \\
0.52 \\
0.44 \\
0.33 \\
0.84 \\
0.98 \\
0.95 \\
0.63 \\
1.06 \\
0.56\end{array}$ & $\begin{array}{l}<0.001 \\
<0.001 \\
<0.001 \\
<0.001 \\
<0.001 \\
<0.001 \\
<0.001 \\
<0.01 \\
<0.05 \\
\quad \text { NSt }\end{array}$ \\
\hline \multicolumn{5}{|l|}{ Unsaturated fatty acids: } \\
\hline $\begin{array}{l}\text { C18:1 Oleic } \\
\text { C18:2 Linoleic } \\
\text { C18:3 Linolenic } \\
\text { C20:4 Arachidonic }\end{array}$ & $\begin{array}{l}5 \\
8 \\
5 \\
5\end{array}$ & $\begin{array}{l}8.32 \\
8.14 \\
8.42 \\
8.00\end{array}$ & $\begin{array}{l}1.42 \\
1.49 \\
1.11 \\
1.92\end{array}$ & $\begin{array}{l}\text { NS } \\
\text { NS } \\
\text { NS } \\
\text { NS }\end{array}$ \\
\hline \multicolumn{5}{|l|}{$\begin{array}{l}\text { Substances activating the } \\
\text { Hageman factor: }\end{array}$} \\
\hline $\begin{array}{l}\text { Glass } \\
\text { Kaolin } \\
\text { Bentonite }\end{array}$ & $\begin{array}{l}7 \\
6 \\
5\end{array}$ & $\begin{array}{l}2.71 \\
2.08 \\
2.20\end{array}$ & $\begin{array}{l}0.52 \\
0.45 \\
0.51\end{array}$ & $\begin{array}{l}<0.001 \\
<0.001 \\
<0.001\end{array}$ \\
\hline Soybean phosphatide & 4 & 9.63 & 1.14 & $<0.02$ \\
\hline
\end{tabular}

* Significance with respect to the control $\mathrm{NaCl}$. $\dagger \mathrm{NS}=$ not significant $(\mathrm{p}>0.1)$.

third. The variation between subjects for both control and experimental values was small.

Other long chain, saturated fatty acids produced similar acceleration of thrombus formation (Table I). In fact, arachidic $(\mathrm{C} 20: 0)$ and behenic (C22:0) shortened thrombus-formation times even more than stearic acid $(\mathrm{C} 18: 0) .{ }^{10}$ On the other hand, there was a progressive lengthening of thrombus-formation time with decreasing chain length of the fatty acids tested: palmitic (C16:0) gave a time of 4.8 minutes; myristic $(\mathrm{C} 14: 0)$, 5.3 minutes; and lauric $(\mathrm{C} 12: 0), 6.8$ minutes. Caprylic $(\mathrm{C} 10: 0)$ and octanoic $(\mathrm{C} 8: 0)$ barely produced shortening of the control value; and caproic (C6:0), with a time of 7.8 minutes, had no significant effect. The addition of a hydroxyl group to stearic acid (hydroxystearic) did not alter the usual accelerating effect of stearic acid.

\footnotetext{
10 Nomenclature of fatty acids refers to the chain length and number of double bonds.
}

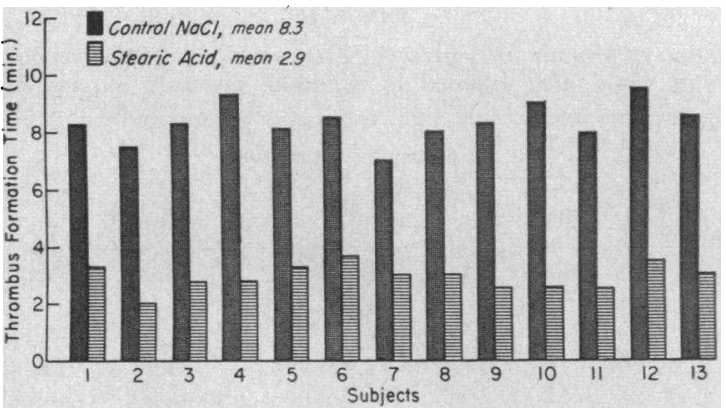

Fig. 2. Shortening of the thrombus-Formation time BY STEARIC ACID.

On the other hand, long chain, unsaturated fatty acids did not accelerate thrombus formation (Table I and Figure 3). Slight changes in the molecular structure produced a great difference in the results. Oleic acid, an unsaturated fatty acid with one double bond, has a chain length identical to that of stearic acid, and its molecular weight is virtually the same ( 282 vs 284 ) ; yet the thrombusformation time with oleic acid was 8.3 minutes as compared with 2.9 minutes with stearic. Other more unsaturated fatty acids of the $\mathrm{C} 18$ series, linoleic $(\mathrm{C} 18: 2)$ with two double bonds and linolenic (C18:3), had the same lack of effect on thrombus formation. The highly unsaturated fatty acid, arachidonic (C20:4), was inactive, in contrast to the saturated fatty acid of the same chain length, arachidic.

The cause of fatty acid acceleration of thrombus formation. In another group of experiments, the thrombus formation of blood was tested with other substances. Glass, kaolin, and bentonite are believed to initiate blood coagulation by activation of the Hageman factor. As has been indicated, the handling of the blood in the test system employed tended to minimize Hageman factor activation. Each of these materials highly accelerated thrombus formation, in fact, similarly to the most

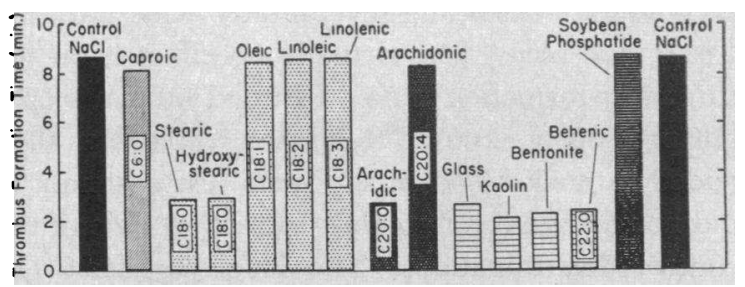

Fig. 3. EFfects of VARIOUS FAtTy ACIdS AND Other SUBSTANCES UPON THE THROMBUS-FORMATION TIME. 
TABLE II

Effect of behenic fatty acid (C22:0) upon thrombus formation in blood also exposed to different amounts of glass*

\begin{tabular}{ccc}
\hline \hline \multicolumn{3}{c}{ Thrombus-formation times } \\
\cline { 2 - 3 } Glass & $\begin{array}{c}\text { Control } \\
(\mathrm{NaCl})\end{array}$ & $\mathrm{C} 22: 0$ \\
\hline$m g$ & $\min$ & $\min$ \\
3 & 8.0 & 3.0 \\
6 & 6.0 & 3.0 \\
9 & 4.0 & 3.0 \\
12 & 3.0 & 2.5 \\
15 & 3.0 & 2.5 \\
75 & 2.0 & 2.5
\end{tabular}

* Test system: $0.9 \mathrm{ml}$ of citrated blood, the designated amount of glass, $0.1 \mathrm{ml}$ of the control $\mathrm{NaCl}$ or $\mathrm{C} 22: 0$, and $0.1 \mathrm{ml} \mathrm{CaCl}$.

potent of the saturated fatty acids, C22:0 (Table I and Figure 3). However, when blood was previously exposed to fine glass and its Hageman factor activated maximally, the addition of C22:0 had no further accelerating effect. When the Hageman factor was incompletely activated by suboptimal quantities of glass, then C22:0 did produce an additive effect (see Table II). Amounts of glass from 3 to $9 \mathrm{mg}$ only partially activated the Hageman factor and C22:0 provided additional shortening of the thrombus-formation time. Amounts of glass, 15 and $75 \mathrm{mg}$, almost completely activated the Hageman factor. These results suggested that both glass and a long chain, saturated fatty acid such as C22:0 (behenic) accelerated thrombus formation by the same mechanism, namely, Hageman factor activation.

Further studies were carried out with blood from the Peking duck. Ratnoff and Rosenblum had shown previously that this species, perhaps along with other fowl, was deficient in the Hageman factor (15). The blood of most ducks has a very long thrombus-formation time, and measures designed to activate the Hageman factor have little effect. The results of a typical experiment are given in Table III. The control $\mathrm{NaCl}$ time was 23 minutes. Glass and several fatty acids (C22:0, $\mathrm{C} 6: 0$, and oleic) had virtually no effect upon the thrombus-formation time. Citrated human blood, not previously exposed to glass surfaces, was then added to duck blood in the same test system. It did not change the thrombus-formation time of the control determination. The Hageman factor of human blood was then activated by exposure to glass before use in the test system. The thrombus- formation time of the duck blood was greatly shortened, from 23 to 9 minutes. Human blood previously incubated with a long chain, saturated fatty acid (C22:0) similarly accelerated the thrombus formation of duck blood.

Concentration of fatty acid and thrombus-formation time. The concentration of the fatty acid necessary to produce these effects was not critical. For example, the 0.1 per cent stearic could be diluted fivefold without any loss of thrombus acceleration effect. Some loss of effect was noted at a tenfold dilution ( 0.01 per cent), but even at a 100 -fold dilution $(0.001$ per cent $)$ the thrombusformation time for stearic was 5.6 minutes $(\mathrm{NaCl}$ control, 8.3 minutes). A 1,000-fold dilution of C18:0, C20:0, and C22:0 did lead, however, to complete loss of any accelerating effect.

The sodium salts of fatty acids had been prepared in 0.1 per cent concentrations. Those fatty acids having similar chain lengths (i.e., the $\mathrm{C} 18$ series) would thus be present in almost identical molar concentrations. However, as the chain length decreased down to $\mathrm{C} 6$, the molarity of a given preparation would increase. Dilution of the short chain fatty acids to provide for a molarity equivalent to the long chain fatty acids only lessened further their slight accelerating effects or, in the case of $\mathrm{C} 6$, could produce no change since this fatty acid was without effect at 0.1 per cent.

Fatty acids and other clotting factors. Acceleration of clotting by long chain, saturated fatty acids occurred only in clotting systems in which the Hageman factor of the blood had been incompletely activated. Fatty acids did not behave as a partial

TABLE III

Thrombus formation with blood from the Peking duck

\begin{tabular}{lc}
\hline \multicolumn{1}{c}{ Test substances* } & $\begin{array}{c}\text { Thrombus- } \\
\text { formation } \\
\text { time }\end{array}$ \\
\hline & $\min$ \\
Control (NaCl) & 23.0 \\
Glass & 22.0 \\
C22:0 Behenic & 19.5 \\
C6:0 Caproic & 19.0 \\
C18:1 Oleic & 23.5 \\
Human blood (not activated) & 21.5 \\
Human blood (glass-activated) & 9.0 \\
Human blood (C22:0-activated) & 7.0 \\
\end{tabular}

* Test system : $1.0 \mathrm{ml}$ of citrated duck blood plus $0.1 \mathrm{ml}$ of one of the test substances. Incubation and the addition of $\mathrm{CaCl}_{2}$ were carried out as in previous experiments. 
thromboplastin For example, the whole blood clotting time of blood not activated was determined in plain glass tubes and in silicone-coated glass tubes with and without the addition of $0.1 \mathrm{ml}$ of 0.1 per cent $\mathrm{C} 22: 0$. When $\mathrm{C} 22: 0$ was not used, $0.1 \mathrm{ml}$ of physiological saline was added to the clotting tubes as a control substance. Blood from eight subjects was tested. C22:0 accelerated the clotting time of blood in silicone-coated tubes from $31.20 \pm 1.96(\mathrm{SD})$ to $8.03 \pm 1.64$ minutes, but did not change appreciably the clotting time in plain glass tubes $(8.32 \pm 1.57$ minutes with saline to $7.77 \pm 1.23$ with $\mathrm{C} 22: 0)$.

Behenic acid (C22:0) had no activity in the thromboplastin generation test, using the reagents collected from normal subjects and stored in glass tubes. In other words, the generation of thromboplastin did not occur when behenic acid (C22:0) was used in place of platelets in this test or when it was substituted in turn for the other reagents (aged serum and barium sulfate-adsorbed plasma).

Soybean phosphatide, used to simulate the action of platelet factor 3 , did not shorten the thrombus-formation time (Table I).

\section{DISCUSSION}

Whenever blood is studied in coagulation systems outside the body, there is always the possibility that the manipulations before actual testing may obscure the factors under study. This especially may be the case in the investigation of thrombosis and hypercoagulability. In the system used in this study, two considerations have special pertinence: first, care was taken to prevent complete activation of the Hageman or glass factor of the blood; second, in the actual test, motion was imparted to the blood so that a thrombus was evolved instead of the usual blood clot.

It is now believed that one important reason for the fluidity of the blood in the body is that the Hageman factor is inactive (15). Once the Hageman factor becomes activated, it in turn activates plasma thromboplastin antecedent (PTA), which further triggers the chain of reactions which form plasma thromboplastin and ultimately culminate in clotting $(16,17)$. Glass particles, bentonite, kaolin, tissue extracts, and other negatively charged colloidal substances $(17,18)$ may activate the Hageman factor (or bind its inhibitor) and thus initiate clotting. Surfaces having a neutral or positive charge apparently do not activate the Hageman factor, and blood exposed to them may remain unclotted for considerable periods of time. Polyethylene, silicone-coated glass, and certain plastics are examples of substances with a neutral or positive charge (18).

Since the work of McBain, Taylor and Laing, it has been known that sodium salts of long chain fatty acids in aqueous solutions form negatively charged colloidal particles known as micelles (19). Micelle formation at a given temperature is related to the solubility of the fatty acid salt or soap and also to its concentration at a given $\mathrm{pH}$. Thus, sodium stearate does not form micelles at extremely low concentrations. With increasing concentration, fatty acid ions coalesce to form the negatively charged ionic micelles (20). The sodium salts of the long chain, saturated fatty acids are relatively insoluble. As the chain length decreases, solubility progressively increases. Salts of long chain, unsaturated fatty acids are also highly soluble $(21,22)$. Perhaps, the more soluble salts of fatty acids do not form ionic micelles at the temperature and concentrations used in this study. Thus, oleic and linoleic, as prototypes of long chain, unsaturated fatty acids, and caproic and octanoic, as examples of short chain, saturated fatty acids, probably did not accelerate thrombus formation because they did not form ionic micelles capable of activating the Hageman factor. The corollary to this hypothesis would be that palmitic, stearic, arachidic, and behenic so markedly accelerated thrombus formation because they did form negatively charged ionic micelles and caused Hageman factor activation.

The range of fatty acid concentration used was well within the range of the unesterified fatty acid fraction that circulates in human blood. The concentration of stearate $(\mathrm{C} 18: 0)$ when mixed for testing with blood was $0.320 \mathrm{mM}$, but the same acceleration of thrombus formation was obtained with a concentration as low as $0.063 \mathrm{mM}$. The other fatty acids have a concentration above or below $0.320 \mathrm{mM}$. Usual figures for the unesterified fatty acid fraction in human blood are between 0.2 and $2.0 \mathrm{mM}(23)$. The fatty acid composition of this fraction includes most of the fatty acids tested in this study and covers the range of concentra- 
tion also. For example, a man in the United States would typically have 12.9 per cent of this unesterified fatty acid fraction as stearic acid, or perhaps 0.05 to $0.1 \mathrm{mM}$ (24). This amount of stearic acid greatly accelerated thrombus formation in the in vitro system. Thus, the test system employed physiological concentrations of some of the fatty acids tested; in particular, stearic, palmitic, oleic, and linoleic.

The relevance of these findings to human disease, particularly to thromboembolic states, is admittedly speculative, yet several points inevitably come up for discussion. Long chain, saturated fatty acids, especially stearic and palmitic, do circulate in the blood. As a part of the very labile unesterified fatty acid fraction, these fatty acids rise and fall in response to certain hormonal and dietary stimuli. Environmental stress, starvation, or the infusion of adrenaline will increase the unesterified fatty acid fraction (23). The notion that thrombosis may occur after moments of stress needs to be mentioned in passing. Beckett and Lewis have found that the incidence of thromboembolic disorders was especially high in obese diabetic patients placed upon rigid reducing diets (8). They postulated that these patients mobilized fat, including saturated fat, from tissue stores. Such starvation would be expected to induce high levels of plasma unesterified fatty acid. It is of interest also that Thomas and Hartroft produced thrombosis of coronary arteries and myocardial infarcts by feeding rats a diet rich in saturated animal fat (butter, lard), cholesterol, sodium cholate, and thiouracil (10). Rats fed the same diet with much less saturated vegetable fats did not develop thrombi and infarcts.

\section{SUMMARY AND CONCLUSIONS}

1. The sodium salts of many different fatty acids were added to human blood and tested in an in vitro thrombus-producing system. Long chain, saturated fatty acids greatly accelerated thrombus formation. These included myristic, palmitic, stearic, arachidic, and behenic acids. The thrombus-formation time was reduced to as little as 2.40 minutes compared with a control 8.33 minutes.

2. Short chain, saturated fatty acids (below 12 carbons in length) affected thrombus formation little or not at all.
3. Long chain, unsaturated fatty acids likewise had no effect. These included oleic, linoleic, linolenic, and arachidonic fatty acids.

4. It was shown that the mechanism whereby long chain, saturated fatty acids accelerated thrombus formation might be through activation of the Hageman factor. These fatty acids had an action similar to that of glass, kaolin, and bentonite. It was speculated that perhaps the negatively charged micelle found in sodium salt solutions of long chain, saturated fatty acids activated the Hageman factor.

\section{ACKNOWLEDGMENT}

The helpful comments of Dr. F. M. Mattson of the Proctor and Gamble Co., Cincinnati, Ohio, are gratefully acknowledged.

\section{REFERENCES}

1. Connor, W. E. Acceleration of thrombus formation by fatty acids. Fed. Proc. 1961, 20, 54.

2. Howell, W. H. The nature and action of the thromboplastic (zymoplastic) substance of the tissues. Amer. J. Physiol. 1912, 31, 1.

3. Macfarlane, R. G., Trevan, J. W., and Attwood, A. M. P. Participation of a fat soluble substance in coagulation of the blood. J. Physiol. (Lond.) 1941, 99, 7P.

4. Connor, W. E., and Carter, J. R. Influence of soybean phosphatide on blood coagulation and its use in the thromboplastin generation test. Proc. Soc. exp. Biol. (N. Y.) 1958, 97, 38.

5. Poole, J. C. F. Effect of certain fatty acids on the coagulation of plasma in vitro. Brit. J. exp. Path. 1955, 36, 248.

6. Pilkington, T. R. E. The effect of fatty acids and detergents on the calcium clotting time of human plasma. Clin. Sci. 1957, 16, 269.

7. O'Brien, J. R. The effect of some fatty acids and phospholipids on blood coagulation. Brit. J. exp. Path. 1957, 38, 529.

8. Beckett, A. G., and Lewis, J. G. Mobilisation and utilisation of body-fat as an aetiological factor in occlusive vascular disease in diabetes mellitus. Lancet 1960, 2, 14.

9. Poole, J. C. F. Fats and blood coagulation. Brit. med. Bull. 1958, 14, 253.

10. Thomas, W. A., and Hartroft, W. S. Myocardial infarction in rats fed diets containing high fat, cholesterol, thiouracil, and sodium cholate. Circulation 1959, 19, 65.

11. Chandler, A. B. In vitro thrombotic coagulation of the blood. A method for producing a thrombus. Lab. Invest. 1958, 7, 110. 
12. Poole, J. C. F. A study of artificial thrombi produced by a modification of Chandler's method. Quart. J. exp. Physiol. 1959, 44, 377.

13. Connor, W. E., and Poole, J. C. F. The effect of fatty acids on the formation of thrombi. Quart. J. exp. Physiol. 1961, 46, 1.

14. Hoak, J. C., Connor, W. E., Warner, E. D., and Carter, J. R. The antithrombotic properties of coumarin drugs. Ann. intern. Med. 1961, 54, 73.

15. Ratnoff, O. D., and Rosenblum, J. M. Role of Hageman factor in the initiation of clotting by glass. Evidence that glass frees Hageman factor from inhibition. Amer. J. Med. 1958, 25, 160.

16. Ratnoff, O. D., Davie, E. W., and Mallett, D. L. Studies on the action of Hageman factor: Evidence that activated Hageman factor in turn activates plasma thromboplastin antecedent. J. clin. Invest. 1961, 40, 803.

17. Soulier, J. P., and Prou-Wartelle, O. New data on Hageman factor and plasma thromboplastin antecedent: The role of "contact" in the initial phase of blood coagulation. Brit. J. Haemat. 1960, 6, 88.
18. Hubbard, D., and Lucas, G. L. Ionic charges of glass surfaces and other materials, and their possible role in the coagulation of blood. J. appl. Physiol. 1960, 15, 265.

19. McBain, J. W., Taylor, M., and Laing, M. E. Studies of the constitution of soap solutions. Solutions of sodium palmitate, and the effect of excess of palimitic acid or sodium hydroxide. $\mathrm{J}$. chem. Soc. 1922, 121, 621.

20. Martin, G. The Modern Soap and Detergent Industry; A Complete Practical Treatise in Two Volumes. Vol. I. Theory and Practice of Soap Making, 2nd ed. London, Crosley Lockwood, 1931, pp. 30-33.

21. Preston, W. C. Some correlating principles of detergent action. J. phys. coll. Chem. 1948, 52, 84.

22. Mattson, F. M. Personal communication.

23. Fredrickson, D. S., and Gordon, R. S. Jr. Transport of fatty acids. Physiol. Rev. 1958, 38, 585.

24. Dole, V. P., James, A. T., Webb, J. P. W., Rizack, M. A., and Sturman, M. F. The fatty acid patterns of plasma lipids during alimentary lipemia. J. clin. Invest. 1959, 38, 1544.

\section{SPECIAL NOTICE TO SUBSCRIBERS}

Post Offices will no longer forward the Journal when you move.

Please notify The Journal of Clinical Investigation, Business Office, 10 Stoughton Street, Boston 18, Mass., at once when you have a change of address, and do not omit the zone number if there is one. 